\title{
Y de un día para otro las cosas cambiaron
}

\author{
Teresa Núñez Fortoul
}

\section{Resumen}

Las cosas cambiaron de un día para otro y todos intentamos surfear la ola lo más rápido posible, pero muchas preguntas y sentimientos comenzaron a presentarse en el camino.

Palabras clave: covid, plataformas, artefactos digitales, educación.

\section{And fRom one day to the NEXT things CHANGED}

\section{Abstract}

Things changed from one day to the next, and we all are trying to pull through the wipeout. However, there are many questions and feelings on the road.

Keywords: coviD, platforms, digital artefacts, education. 
"Y de un día para otro las cosas cambiaron"

Teresa Núñez Fortoul

Vol. 22, Núm. 1, enero-febrero 2021

Revista Digital Universitaria

Teresa Núñez Fortoul

terenufo@gmail.com

orcid.org/0000-0003-2860-8061

Graduada del Diplomado "Tránsitos XxI-XxI", por el Centro Nacional de las Artes. Maestra y licenciada en Comunicación por parte de la Universidad Iberoamericana de la Ciudad de México. Cuenta con experiencia docente en el Colegio de Arte de la Universidad Claustro de Sor Juana donde enseñó el curso "Introducción de estudios sociales sobre ciencia y tecnología", también fue docente en el Departamento de Comunicación Digital en el Centro del Diseño, Cine y Televisión con el curso "Narrativas transmedia y Cultura digital". Ha recibido dos becas: la beca nacional 2014-2016 y la beca nacional de movilidad del Consejo Nacional de Ciencia y Tecnología ConAcrt. Recibió mención honorífica en su tesis de maestría. Además, fue ganadora de la convocatoria del xxv aniversario del Centro Nacional de las Artes 2019, con la pieza "Coordenadas".

$\mathrm{D}$ ejé de ver a mis alumnas y alumnos, la socialización cara a cara desapareció y lo único que podíamos hacer era hablarnos entre artefactos digitales. Lo que más me preocupaba no era no verlos, sino intentar replicar las maneras en las que ellos aprendían, intercambiaban saberes y creaban controversias en el salón.

La llegada de Google Classroom nos asustó a todos (a estudiantes, profesores e instituciones). El formato era diferente, la comunicación con los estudiantes era breve y vertical, la cantidad de horas de trabajo incrementó, pero logramos sobrevivir. Sin embargo, atravesar por la educación en línea puso en perspectiva muchas cosas, por ejemplo: planear la clase para una plataforma en específico, intentar "replicar" la relación enseñanza-aprendizaje, pensar en ejercicios o actividades que fueran "visibles" para la institución y preparar los reportes semanales. Entre tantos formatos y ejercicios controlados por una plataforma, no me sentía cómoda. La educación en línea me parecía un lugar en donde la creatividad no fluía, regresábamos al esquema tradicional de enseñanza y los estudiantes no compartían saberes. "¡No nos podíamos despegar de la computadora, ni teníamos tiempo de rascarnos el ombligo!", exclamaba uno de mis alumnos. Sin duda, ahora que lo escribo me doy cuenta de que me pasó lo mismo, solamente veía una pandemia, un distanciamiento social y una sana distancia. 
Encerrarse al parecer era la única opción así que las fiestas en Zoom, cuidar que tu cámara no invadiera tus espacios íntimos, las Netflix-parties, los juegos en línea y las videollamadas entre familiares empezaron a crear nuevas relaciones que no contemplábamos.

Las vacaciones escolares Ilegaron y me cuestionaba: ¿por qué la enseñanza en línea no se está transformando? La mediación entre nosotros y la tecnología ahí seguía, pero ¿por qué teníamos que atenernos a esos espacios, los cuales no eran los que mi materia necesitaba?

Todo esto lo detonó la pandemia y, desde mi punto de vista, las plataformas de enseñanza en línea siguen respondiendo a la visión tradicional de la educación, situación en la que yo no me encuentro como docente. ¿Cómo romper la verticalidad en el espacio virtual de enseñanza? y ¿cómo lograr que el intercambio de ideas, fuera del salón exista en el mundo virtual?

\section{Cómo CITAR ESTE ARTículo}

* Núñez Fortoul, Teresa. (2021, enero-febrero). Y de un día para otro las cosas cambiaron. Revista Digital Universitaria (RDU), 22(1). Dol: http://doi.org/10.22201/ cuaieed.16076079e.2021.22.1.3 